(RESEARCH ARTICLE)

\title{
Application of ICTs in agricultural extension delivery services in Benue State, Nigeria
}

\author{
Attah Agbo Joseph, Waya Dominic Teryila and Otene Victor Akwu * \\ Department of Agricultural Extension and Communication, Federal University of Agriculture, Makurdi.
}

Publication history: Received on 08 April 2020; revised on 14 April 2020; accepted on 15 April 2020

Article DOI: https://doi.org/10.30574/wjarr.2020.6.1.0088

\begin{abstract}
This study examined the application of information and communication technologies (ICTs) in agricultural extension delivery services in Benue State, Nigeria. Forty respondents were selected. Primary data were used, and collected using a structured questionnaire. Data were analyzed using descriptive statistics. Research findings revealed that respondents had low level of access to ICT facilities, as the mean value of their access level for most of the ICT facilities was below the medium scale (2.00). The ICTs with high access were radio $(\bar{x}=2.50)$, television $(\bar{x}=2.35)$ and Mobile phones $(\bar{x}=$ 2.78). The respondents had a high usage of mobile phones $(\bar{x}=4.00)$, radio $(\bar{x}=4.00)$, television $(\bar{x}=3.83)$, internet connected computers $(\bar{x}=3.00)$ and printers $(\bar{x}=2.08)$. The constraints to the application of ICTs by the respondents were infrastructural, financial and technical in nature. Based on these findings, it was recommended that ICT facilities be provided in the work places of extension agents, provision of infrastructure required for the operation of ICTs, and provision of financial assistance to extension agents with respect to procurement and maintenance of ICTs.
\end{abstract}

Keywords: Application; Information; Communication technology; Extension delivery

\section{Introduction}

Agricultural extension services include transferring knowledge to farmers, advising and educating farmers in their decision making, enabling farmers to clarify their own goals and possibilities, and stimulating desirable agricultural developments [1]. The effectiveness of extension service delivery to farmers is dependent on the flow of relevant information to the farmers. The unfavourable ratio between extension agents and farmers in Nigeria will make it almost impossible for the extension agents to be efficient in information dissemination if they are to meet with all the farmers. The alternative to making contact with farmers without necessary maintaining a face-to-face contact is the application of information and communication technologies.

There is growing recognition that extension workers and members of rural communities have needs for information and appropriate learning methods that are not being met [2,3]. In the midst of these challenges, extension workers are grappling with the question of how best to harness information and communication technologies (ICTs) to improve rural livelihoods. The use of ICTs in agricultural extension and rural development has significantly increased in many countries where it has provided a medium to adequate access to agricultural information [4].

Ovwigho et al. [5] defined ICTs as an omnibus term that encompasses computer and telecommunication technology. According to Omotesho et al. [6], ICTs generally refer to an expanding assembly of technologies that are used to handle information and aid communication. These include hardware, software, media for collection, storage, processing, transmission and presentation of information in any format (i.e., voice, data, text and image), computers, the Internet, CD-ROMs, email, telephone, radio, television, video, digital cameras, etc.

\footnotetext{
${ }^{*}$ Corresponding author: Otene Victor Akwu
} 
Benue State, Nigeria is a highly agrarian State, with about $70 \%$ of the population engaged in agricultural activities. These farmers would need agricultural information for profitable production and marketing of their produce, and this information can get to them through ICTs. While so much emphasis has been placed on the use of ICTs by farmers, it is necessary for extension agents to have access to the ICTs, and also use them. This is because the extension agents cannot communicate using ICTs that they do not have access to, and use. This study was therefore carried out to achieve the following objectives:

- Ascertain the level at which extension workers have access to ICT facilities in the study area;

- Identify the frequently used ICT facilities by extension workers in the study area; and

- Determine the constraints to the application of ICTs in agricultural extension service delivery as perceived by the extension workers in the study area.

\section{Methodology}

\subsection{The study area}

The study was carried out in Benue State, one of the North-central states in Nigeria. According to Wikipedia, the State lies between latitudes $6^{0} 25^{\prime} \mathrm{N}$ and $8^{0} 8^{\prime} \mathrm{N}$ and longitudes $7^{0} 47^{\prime} \mathrm{E}$ and $10^{\circ} \mathrm{E}^{\prime}$ [Wikipedia, https://en.wikipedia.org/wiki/Benue_State, Last accessed on 02/04/2020]. It is surrounded by five states; Nassarawa to the North, Taraba to the Northeast, Cross River to the South, Enugu to the Southwest and Kogi to the West. There is also a short international boundary between the state and the Republic of Cameroun along Nigeria's Southeast border. Benue State covers a land mass of 2,753,077 $\mathrm{Km}^{2}$, and has a population of 4,253,614 persons in 2006, projected to 5,741, 800 persons in 2016 [Citypopulation, https://www.citypopulation.de/Nigeria-Cities.html, Last accessed on 01/04/2020].

Benue State is referred to as the food basket of the Nigerian nation because of its diverse rich agricultural produce which include yams, rice, beans, cassava, soyabeans, benniseed , maize, sorghum, millet, tomatoes. Livestock such as poultry, goats, sheep, pigs and cattle are also reared. Others include cocoyam, sweet potatoes, millet, beans, cassava, and a wide range of other crops like groundnuts, ginger and sugar cane. It is the only notable producer of soyabeans in the country. Tree crops like oil palm, cashew, mango, coconut, bananas and citrus also grow very well in the State.

\subsection{Population and sample selection}

The target population for this research work is extension agents in Benue state, Nigeria. The entire population was studied, which consists 40 extension agents in the three agro-ecological zones in the state.

\subsection{Methods of data collection and analysis}

Primary data was used for this study, collected using a well-structured questionnaire designed to collect information to satisfy the objectives of the study. The collected data were analyzed using descriptive statistics such as frequency counts, percentages, means and Likert-type scales. The questionnaires were validated, and found reliable.

\section{Results and discussion}

\subsection{Level of access to ICT facilities by the respondents}

The result on the level of access to ICT facilities by the respondents is presented in Table 1. It was found that extension agents had mean rating scores of between 2.35 and 2.78 for 3 out of the 10 variables (ICTs facilities) on the scale, which are higher than 2.00, the medium of the scale. This confirms that the respondents had low level of access to ICT facilities. The ICTs with high accessibility were radio $(\bar{x}=2.50)$, television $(\bar{x}=2.57)$ and phone (handset) $(\bar{x}=2.78)$. This finding further confirms the report that radio is widely used among rural people, indeed as an important medium of agricultural information dissemination as reported by Aderinto et al. [7] and Obinna and Nzeakor [8]. The use of mobile phones was also high, and is a tool that can be employed in communicating with farmers. 
Table 1 Distribution of Respondents according to Level of Access of ICT Facilities (n = 40)

\begin{tabular}{lllll}
\hline ICT Facilities & \multicolumn{2}{c}{ Level of Access } & Mean \\
& Moderate & High & \\
\hline Radio & $1(2.50)$ & $18(45.00)$ & $21(52.50)$ & 2.50 \\
Television & $0(0.00)$ & $26(65.00)$ & $3(35.00)$ & 2.35 \\
Phone (Handset) & $0(0.00)$ & $9(22.50)$ & $31(77.50)$ & 2.78 \\
Internet Connected Computer & $1(2.50)$ & $17(42.50)$ & $22(55.00)$ & 1.53 \\
Cassette recorder/player & $2(5.00)$ & $34(85.00)$ & $4(10.00)$ & 1.05 \\
CD-ROM & $3(7.69)$ & $36(92.31)$ & $0(0.00)$ & 0.92 \\
Mobile Cinema & $2(5.13)$ & $31(79.49)$ & $6(15.38)$ & 1.10 \\
Projector & $12(30.00)$ & $28(70.00)$ & $0(0.00)$ & 1.70 \\
Geographical Information System & $27(69.23)$ & $10(25.64)$ & $2(5.13)$ & 1.36 \\
Printer Machine & $12(69.23)$ & $27(67.50)$ & $1(2.50)$ & 1.73 \\
\hline
\end{tabular}

Figures in parenthesis are percentages

\subsection{Frequency of use of ICT facilities by the respondents}

The result on the frequency of use of ICT facilities by the respondents is presented in Table 2. Research findings revealed that out of 10 ICT facilities listed, 5 facilities were frequently used by extension agents as their mean rating score were higher than 2.50 , the medium scale. The frequently used facilities include radio $(\bar{x}=4.00)$, television $(\bar{x}=3.83)$, phone (handset) $(\bar{x}=4.00)$, internet connected computer $(\bar{x}=3.00)$ and printer machine $(\bar{x}=2.88)$. It implies that considerable proportion of the extension agents had adopted or frequently use one ICT facilities or the other and these could be attributed to high level of accessibility and awareness of these ICT facilities.

This is an indication that communication with farmers will be possible through the ICTs that the extension agents use frequently, if farmers also have access to, and use the same technologies for communication. Isomorphic ICT facilities between extension agents and farmers will facilitate the delivery of agricultural information to farmers. Otene et al. [9] reported a high use of radio by farmers in some parts of Benue State, while the use of mobile phones by farmers in some parts of the state was reported by Attah et al. [10].

Table 2 Distribution of Respondents according to Frequency of Use of ICT Facilities $(n=40)$

\begin{tabular}{llllll}
\hline \multirow{2}{*}{ ICT Facilities } & \multicolumn{2}{l}{ Frequency of Use } & & Mean \\
& Never used & Monthly & Weekly & Daily & \\
\hline Radio & $0(0.00)$ & $0(0.00)$ & $0(0.00)$ & $40(100.00)$ & 4.00 \\
Television & $0(0.00)$ & $0(0.00)$ & $7(17.50)$ & $33(82.50)$ & 3.83 \\
Phone (Handset) & $0(0.00)$ & $0(0.00)$ & $0(0.00)$ & $40(100.00)$ & 4.00 \\
Internet Connected Computer & $2(5.00)$ & $8(20.00)$ & $18(45.00)$ & $12(30.00)$ & 3.00 \\
Cassette recorder/player & $5(12.50)$ & $27(67.50)$ & $8(20.00)$ & $0(0.00)$ & 2.08 \\
CD-ROM & $17(42.50)$ & $18(45.00)$ & $5(12.50)$ & $0(0.00)$ & 1.70 \\
Mobile Cinema & $19(47.50)$ & $17(42.50)$ & $4(10.00)$ & $0(0.00)$ & 1.63 \\
Projector & $4(10.00)$ & $26(65.00)$ & $10(25.00)$ & $0(0.00)$ & 2.15 \\
Geographical Information System & $13(32.50)$ & $20(50.00)$ & $5(12.50)$ & $2(5.00)$ & 1.90 \\
Print machine & $2(5.00)$ & $9(22.50)$ & $21(52.50)$ & $8(20.00)$ & 2.88 \\
\hline
\end{tabular}




\subsection{Constraints faced by respondents in application of ICT facilities in agricultural extension service delivery}

The constraints faced by respondents in the application of ICTs were determined using factor analysis, and the result is presented in Table 3. Three factors were identified as constraints. These were infrastructural, financial and technological constraints. The significant infrastructural constraints were lack/unstable power supply (5.43), poor ICT facilities (3.95), bad ICT network service (4.21) and lack of access to ICT facilities in rural areas (3.97).

Significant financial constraints were high cost of ICT facilities (5.83) high cost of maintenance of ICTs (4.31) and high cost of alternative power supply (3.81). The technological factors with high loading were lack of technical know-how (4.46) and lack of ICT training programmes for extension agents. It is expected that provision of solutions to the problems faced by the extension agents will facilitate their increased used of ICTs and this could mean more effective communication with farmers.

Table 3 Distribution of Respondents according to Constraints Faced in Application of ICT Facilities.

\begin{tabular}{llll}
\hline Constraints & Factor 1 & Factor 2 & Factor 3 \\
\hline High cost of ICT facilities & 3.18 & $5.83^{*}$ & 2.23 \\
Lack/unstable power supply & $5.43^{*}$ & 1.67 & 1.73 \\
Lack of technical know-how & 1.92 & 3.12 & $4.46^{*}$ \\
Poor ICT infrastructures & $3.95^{*}$ & 0.87 & 1.10 \\
Bad ICT network service & $4.21^{*}$ & 2.45 & 2.28 \\
High cost of maintenance of ICTs & 2.84 & $4.31^{*}$ & 1.72 \\
High cost of alternative power supply & 1.18 & $3.81^{*}$ & 1.69 \\
Lack of on extension communication policy by government & 3.01 & 2.16 & 3.38 \\
Lack of ICT training programme for extension workers & 2.17 & 1.95 & $4.96^{*}$ \\
Lack of access to ICT facilities in rural areas & $3.97^{*}$ & 2.53 & 1.73 \\
\hline
\end{tabular}

\section{Conclusion}

The findings of this study reveal a population with low access to ICT facilities. The ICTs frequently used by the respondents include mobile phones, radio, television, internet connected computers and printers. The constraints that the respondents face in the use of ICTs were infrastructural, financial and technical in nature. It was based on these findings that the following recommendations are made:

- ICTs should be provided in the offices of extension agents. This will increase their access to ICTs.

- The infrastructure required for operation of ICTs should be provided by the governments at all level, as infrastructural constraint was identified as retarding the application of ICTs.

- Provision of financial assistance to the extension agents, with regards to the purchase and maintenance of ICTs should be considered by the government, having identified financial constraint to the application of ICTs.

\section{Compliance with ethical standards}

\section{Acknowledgments}

We acknowledge the support from the extension agents in Benue State, Nigeria for their cooperation and provision of the data required for this research. We also acknowledge the management of Levite Business Centre for accurate analysis of the collected data.

\section{Disclosure of conflict of interest}

There is no conflict of interest in this publication. 


\section{References}

[1] Xiaolan F and Shaheen A. (2016). The impact of mobile phone technology on agricultural extension services delivery: Evidence from India. The Journal of Development Studies, 52(11), 1561-1576.

[2] Tiwari M, Tiwari NS and Sharma R. (2015). Information and communication cechnology in academic libraries: How they are important today? International Journal of Applied Research, 1(11), 668-672.

[3] Salau ES and Saingbe ND. (2008). Access and utilization of information and communication technologies (ICTs) among agricultural research and extension workers in selected institutions in Nasarawa State, Nigeria. Journal of Production, Agriculture and Technology, 4(2), 1-11.

[4] Syiem R and Saravanan R. (2015). Access and usage of ICTs for agricultural and rural development by the tribal farmers in Meghalaya State of North-East India. Journal of Agricultural Informatics, 6(3), 24 - 41.

[5] Ovwigho BO, Ifie PA, Ajobo RT and Akor EI. (2009).The availability and use of information communication technologies by extension agents in Delta agricultural development project, Delta State Nigeria. Journal of Human Ecology, 27(3), 185-188.

[6] Omotesho KF, Ogunlade IO and Muhammad L. (2012). Assessment of access to information and communication technology among agricultural extension officers in Kwara State, Nigeria. Asian Journal of Agriculture and Rural Development, 2(2), 220-225.

[7] Aderinto A, Agbelemoge A and Dada OM. (2017). Effectiveness of extension service delivery and productivity of cassava farmers in Southwestern Nigeria. Journal of Agricultural Sciences, 12, 14-23.

[8] Obinna LO and Nzeakor FC. (2014). Improving agricultural extension delivery service through the use of information and communication technology in Abia State, Nigeria. Journal of Science and Technology, 4 (1), 2258.

[9] Otene VA, Okwu OJ and Gwaza SS. (2015). Barriers to the use of radio as a channel of agricultural information by farmers in Ushongo local government area of Benue State, Nigeria. Journal of Agricultural and Food Information, $16(4), 326-336$.

[10] Attah AJ, Otene VA and Waya DT. (2020). Assessment of internet and mobile phone usage in enhancing fish farming in Makurdi local government area of Benue State, Nigeria. International Journal of Research and Scientific Innovation, 7 (3), 115-120.

\section{How to cite this article}

Attah AJ, Waya DT and Otene VA. (2020). Application of ICTS in agricultural extension delivery services in Benue State, Nigeria. World Journal of Advanced Research and Reviews, 6(1), 100-104. 